\title{
The Drug Industry
}

\section{Are the drug-regulatory agencies paper villains?}

\author{
TONY SMITH
}

Many doctors seem to believe that governmental controls on drug safety came into being only as a result of the thalidomide disaster. In fact, the first public demands for government action on drug safety came as a result of the fatal poisoning in 1938 of 107 Americans by a liquid formulation of sulphanilamide. The manufacturers found that the drug was insoluble in water and made up an elixir based on diethylene glycol. No toxicity tests were carried out before the mixture was given out to dentists and doctors. The scandal that resulted from the deaths led to the United States Congress passing a law requiring all new products and reformulations to be submitted to the Food and Drug Administration.

In the early $1960 \mathrm{~s}$, however, most countries still had no formal machinery for regulating the introduction of new drugswhen the impact of the thalidomide affair was sufficiently dramatic for there to be a public demand for official bodies to monitor drug safety. In Britain Sir Derrick Dunlop became the first chairman of the Committee on Safety of Drugs, which acted without statutory powers until the establishment of the Medicines Commission with its Committee on Safety of Medicines. Most Western countries now have comparable organisations-and so do an increasing proportion of the nations of Africa, Asia, and South America.

\section{Assessment of new drugs}

What happens nowadays when a pharmaceutical manufacturer begins the development of a new drug ? First of all, he must assemble data on the drug's toxicity in animals-on its acute (single dose), subchronic (10 days), and chronic (six months plus) toxicity; on reproduction and teratogenicity; often on carcinogenicity (testing for the animals' lifetimes); and on mutagenicity in laboratory tests. Only if these animal screening tests give essentially negative results will the drug go forward for studies in man.

Assessment of new chemical entities in man progresses in four phases. Firstly, the drug is given to human volunteers in small doses to compare the results with the pharmacological data obtained in animals and to see how man tolerates the compound (phase I studies). Phase two studies, which in Britain have until very recently always required a clinical trials certificate from the Department of Health and Social Security, consist of limited trials in perhaps 40 or 50 patients to see whether or not the drug is effective therapeutically as well as being pharmacologically. If the drug passes through its phase two studies satisfactorily it can enter phase three-wide-scale clinical trials with many more investigators. This phase may be prolonged if extensive trials are thought necessary or if-as is

British Medical Journal, London WC1H 9JR

TONY SMITH, BM, BCH, deputy editor often the case-the regulatory agency defers reaching a decision on the drug or requests additional testing on animals.

Once the phase three studies are complete-and any remaining doubts or uncertainties are resolved on the animal data-the drug can be marketed. Phase four studies consist of postmarketing surveillance-the processes of collection of data on side effects from individual prescribing doctors-which has become very fashionable in the past few years.

\section{What happens in practice}

In Britain (and most of its European neighbours) 20 years have now passed since the process of drug regulation began. In that time these organisations seem to have become bogged down in bureaucracy. Let $\mathrm{Dr} \mathrm{T}$ Vossenaar, of Organon International, Holland, take up the story. "I was recently working on the file of a new drug- 7000 pages in 24 volumes-which had been submitted to a registration authority. The official concerned came back to us with some questions. It was obvious that the person asking the questions had not read the file-all the answers were in it-but his time was running out and he had to do something."

The files are so big, Dr Vossenaar went on, because the companies have an obligation to include all the data they have recorded. The regulatory agencies argue that they are the judges of what is relevant or irrelevant-they claim the prerogative of distinguishing which are the important facts from this mass of material. But since the agencies are also understaffed the result is that they operate in an atmosphere of bureaucratic delay.

Dr Rondel (Director of Clinical Research (Europe) at Bristol Myers) had had the same sort of experience. "In some countries," he commented, "you get the so-called creeping requirement. As you produce answers to one set of questions another set is posed. I am sure this could at least be reasonably construed as a stalling device." And the delays are undoubtedly lengthening and causing increasing concern-especially in the United States, where the concept of the drug-lag has become familiar to the public at large.

\section{Drug lag in the United States}

Indeed, the American public has come to realise that the system that "protected" it from both thalidomide and practolol may also have delayed for many years the introduction into the United States of effective, life-saving drugs developed in Europe. At one time the Food and Drugs Administration was seen as a scientifically motivated check on the aggressive commercialism of the multinational drug industry. Now it has acquired a new image of bumbling, cautious ineptitude as a result of critics such as Dr William $M$ Wardell. Wardell has claimed, for example, that in 19762.6 times as many new drugs were introduced in Britain as in the United States; the ratio 
was 2.5 for France and 3.6 for Germany. ${ }^{1}$ On average, each year the three European countries introduced 2.9 times as many drugs as the United States.

Wardell quoted the report of the President's biomedical research panel: "... there is a different kind of hazard to public health posed by the prolonged delays and great costs of developing new and potentially useful drugs which the FDA's own protective systems have imposed. In some respects the agency has become a formidable roadblock."

Dr Donald Kennedy, the FDA Commissioner at the time of Wardell's attacks, countered by arguing that the FDA's delays were no worse than those imposed by other countries. ${ }^{2}$ He claimed that the decline in the rate of introduction of important new chemical entities was due to exhaustion of the basic knowledge on which earlier breakthroughs had been based. "Regardless of the regulatory climate here or elsewhere," said Dr Kennedy, "the downward trend is likely to be reversed only by basic innovations in molecular biology, fresh insights in our understanding of certain disease mechanisms, or new therapeutic concepts." And, like other informed observers, Kennedy explains much of the decline in innovation as due to the increase in medical knowledge of pharmacokinetics, analytical toxicology, and the need to test for carcinogenic, mutagenic, and teratogenic effects.

"Since 1967, when the FDA approved propranolol," says Kennedy, "no attempt was made to market a beta-blocker in the United States until mid November 1976, when a new drug application was submitted for metoprolol. A major reason for the delay was the suspicion that a number of beta-blockers might be tumorigenic and the resulting requirement that long-term animal studies be undertaken to investigate this possibility." Kennedy went on to claim that at least four of the 11 drugs on which studies had been completed had proved tumorigenic in test animals. "The FDA's 1972 decision to require long-term carcinogenic-effect testing before clinical use has spared patients in the United States a potentially dangerous kind of exposure."

\section{Ever more tests}

It is no surprise that doctors working in the drug industry take a rather different view. Their major criticism is that in their 20 years of experience the drug regulatory agencies have reacted to every crisis and public scandal by adding to the mandatory tests without making any compensatory deletions from the procedures required.

"Every time a new test is developed," said Dr Smith, Director of Clinical Research and Drug Development with Hoffmann-La Roche (Basle), "bureaucrats see it as a good idea-something to reassure their bosses and the politicians behind them. So there is strong motivation to bring in more and more constraints. Many regulatory authorities have laid down very strict guidelines for toxicity testing which most animal toxicologists regard as a load of nonsense. Standardising is convenient for bureaucrats but it does not permit the flexibility necessary for exploring new ways of evaluation."

Dr Janssen took a similar line. He thought, for example, that carcinogenicity studies made no real sense. "Most rat strains have a survival of between 18 and 24 months," he explained, "so that after the two years of a mandatory study half the control rats are dead, and the results are meaningless"-a view echoed by $\mathrm{Dr}$ Gelzer, who blamed regulations for a mass of redundant and useless research that amounted to "delegation of responsibility on to millions of rats and rabbits."

Looking at the current scene from a standpoint outside the industry, Dr Dunne thought that it was virtually impossible to demonstrate the efficacy or otherwise of most of the animal tests in current use. The problem as he saw it was that animal models were sometimes-but by no means frequentlyindicators of potential toxicity of drugs in man. "While that fallibility exists," he went on, "and while drugs still emerge on to the markets of highly developed countries that are later found to have unacceptable toxicity, then I cannot see regulatory agencies doing anything other than becoming more stringent. They will say that if a battery of tests was not sufficient to serve its purpose in this particular case that more tests must be added."

Why did the testing agencies take this line rather than saying that if tests had been ineffective they should be scrapped? The attitude, said Dr Dunne, was best explained by an analogy. "The agency sees itself as building a wall of bricks with every test a brick-as a dam to stop any seepage of foul water past it. If the agency sees a hole in the dam it doesn't replace one brick by another-it adds another layer of bricks."

The central problem-as seen by the research teams within the industry -is that the drug regulatory agencies are concerned with safety and the protection of the public rather than with co-operating with the pharmaceutical industry to get new drugs on to the market. Their attitudes are negative and defensive rather than constructive. "The basic requirements in pharmacy, chemistry, pharmacology, and toxicology are constantly being augmented," said Dr Rondel, "but no real attempt is being made to evaluate these and pull out stuff which has been shown to be irrelevant." Nor do the pharmaceutical companies like recent trends within the European Economic Community and other multinational grouping towards some system of uniformity in drug regulations. At present, companies wanting to test a new drug can often carry out phase one studies in a country such as Belgium without too much bureaucratic interference. The prospect of having to conform with EEC guidelines fills the companies with foreboding. "The obvious danger," said Dr Rondel, "is that the requirements would be framed at the level of the most stringent. All governments are going to play safe and the result will be a summation of the individual countries' regulations rather than any sort of consensus."

\section{Uniform system}

In principle, a uniform system would make a lot of sense. Dr Gelzer, for example, pointed to the analogy with the United States, which has a single Federal agency. Within Europe, however, there would be additional, complicating factors. "The Germans, French, and English have their own cultural specificities in medicine in just the same way as in agricultural matters," said Dr Gelzer. "And with third world countries there is also the matter of national pride." All these pressures were acting against a single, simple, and unified system. "The World Health Organisation has discussed the possibility of setting us a standing committee of drug regulatory authorities, aimed long term at providing a mechanism for some harmonisation of procedures, attitudes, and decisions," said Dr Dunne. "But life is made difficult for us, because emotive issues such as the side effects of practolol have given governments the feeling that they need to retain autonomous control over drugs. They feel a direct responsibility to their publics-and they have great sensitivity to consumer safety."

The agencies are made up of civil servants, with their own hierarchy of responsibility upwards and a further tier of responsibility to politicians and through them to the public. During their 20 years of operation many of the agencies (and their political masters and spokesmen) have come under repeated attack whenever a drug has been found to have unacceptable or unexpected side effects. Hardly ever-except in the United States-have agencies been publicly criticised for delaying the introduction of new drugs or for adding unnecessarily to their development costs. Even in the United States, where the drug lag has had most publicity, the defence by the FDA -that it saved the American public from thalidomide and practolol-has proved effective in allaying public doubts.

So, as behavioural psychologists would say was inevitable, 
the drug regulatory agencies have become slower and more cautious. Even those such as the British Committee on Safety of Medicines, with a high reputation for scientific integrity, have come under repeated attack when they have resisted demands (based on inadequate evidence) to ban drugs such as saccharine or Debendox.

Why, then, are the public pressures on the drug regulatory agencies all from one direction? How have delays and refusal to take decisions become seen as virtues by the politicians responsible for drug safety? These attitudes will be discussed in my next article.

\section{References}

1 Wardell WM. A close inspection of the "calm look." Rhetorical amblyopia and selective amnesia at the Food and Drug Administration. $\mathcal{F} A M A$ 1978;239:2004-11.

${ }^{2}$ Kennedy D. A calm look at "drug lag.” $\mathcal{F} A M A$ 1978;239:423-6.

\section{MATERIA NON MEDICA}

\section{The world of the midiscopic}

Macroscopic appearances are there for all who have eyes to see them. Most doctors are anyway acquainted with the microscopic appearances of various plants and animals and of the human body, if only from their medical student days. It is surprising then what a great revelation it is to many people if they begin to make use of a simple $\times 8$ or $\times 10$ hand lens, and observe the world between - the world of the midiscopic. I was first advised to buy a hand lens in 1944, when my sight was still very good and I didn't need even reading glasses. The advice was given to me at Crookham in the summer of 1944 when I was doing my initial three weeks' training in the RAMC. One of the instructors advised that we should have a hand lens as an aid to map reading. That was my introduction to the hand lens and I don't think I have ever failed to have one in my pocket since. Certainly it has become increasingly useful over the years for the original purpose of map reading. But apart from this it has opened up a world of which few people seem to be aware unless they have made any form of natural history a special hobby or interest. My own particular interests have been in botany and more recently in the study of a particular group of plants - the bryophyta, or mosses and liverworts. The beauty and incredible anatomy revealed by looking with a hand lens at almost any plant has to be seen to be believed. Many doctors have long forgotten for instance the Compositae, one of the largest natural orders of plants in the world. One very common English member, the daisy, has its own head made up of 200 or so tiny florets, each a perfect little flower in miniature. Similarly fascinating are the very different florets of the grasses-represented by some 150 species in the UK. But this is only the beginning of a lifetime's study or a study that could last an infinity of lifetimes. As far as mosses go there are nearly 700 species in the British Isles and there is certainly plenty of scope for study. What worlds the hand lens can open up in all forms of natural history as well as being of practical help in day-to-day medicine when looking at, say, a rash or a rodent ulcer. I would stress that it is well worth while getting a good small hand lens with a $\times 8$ or $\times 10$ magnification rather than the large Sherlock Holmes variety with a $\times 2$ or $\times 3$ magnification only.-P E JACKSON (consultant physician, Stamford, Lincolnshire).

\section{The Corbett Collection}

The Munros are well known to hill walkers and climbers as the Scottish peaks of $3000 \mathrm{ft}$ or more, but their little brothers, the Corbetts, are less familiar. They are the peaks with altitudes of 2500 to $3000 \mathrm{ft}$. We set ourselves a challenge as we conversed in the medical staff coffee room-namely, the collection of all nine Corbetts in the south of Scctland in one weekend.

Seven of us left the hill road, north of Newton Stewart, early on a Saturday morning in July in grey Galloway weather. The first series of peaks was traversed in enveloping cloud with wet conditions overhead and underfoot. Accurate compass work was required to lead us to the cairns of Shalloch on Minnoch, Kirriereoch, and Merrick in turn. Thoroughly soaked and cold, we descended from the heights into the clear valley of Loch Enoch and the Dungeon of Buchan before ascending into the mirk to scale Corserine, the round-topped reigning peak of the Kells range. We crossed another valley, and the last summit of the day, Cairnsmore of Carsphairn, lay before us, concealed in the deepening gloom. We completed 25 miles of the Galloway Hills in appalling summer weather.

On Sunday we assembled in the Moffat hills in worse conditions, wind and horizontal unremitting rain with only a little globe of hazy vision around us. We gained our first top, Hartfell, without difficulty but our compass and map reading let us down as we strove to reach White Coomb. After floundering for a time in the appropriately named Rotten Bottom, we retrieved our bearings. Wearied and wet, we descended to the road before facing the final two peaks, Broad Law and Cramalt Craig. Still in driving rain, we completed our last seven miles and $2500 \mathrm{ft}$ of ascent in just two hours, such was the strong incentive of the finishing post.

As we left the hill at 8 o'clock breaks appeared in the cloud, the wind fell, and golden sunshine bathed the lowland hills. We, the four survivors, had stood on nine Corbetts with no view from any one of them. We had tramped 40 miles of wilderness in July weather-cloud rain, and wind. As a feat, it hardly compares with the Bob Graham Round in Lakeland or the Six Peaks Walk in the Cairngorms but it does provide a hill walking exercise for those who love the high places. The weather cannot be guaranteed.-ANDREW ARMSTRONG (consultant physician, Dumfries).

\section{Bran, boards, and broadcasting}

Working in front of a health board is something of a challenge. Subjects arise without warning and informed replies are expected. A description of Lassa fever, the infectivity of scabies, the optimum size of a district general hospital, and a definition of urban deprivation-all have been asked of me in my time. Moreover, the latest medical discoveries as revealed by the popular press are sure to be raised, along with the newest diet, the breakthrough, and the miracleworking wonder drug. In this respect, keeping up with the $B M F$ comes a poor second to the Sunday supplements.

An additional hazard is the press. They sit at the back of the room quietly taking notes. It is all too easy to forget them. An injudicious remark, a careless aside, or a simple joke and, before you know it, there you are in the local papers. Or worse, being invited to appear on television.

This happened to me recently. In response to a question I waxed eloquent on the subject of bran, together with personal habits and the need to educate the public. The next day found me in the television studio. Bran had become news. I sat in a sort of up-market outpatient department feeling unwell as familiar faces drifted in and out, carrying cups of coffee. After disclaiming proficiency in darts, land reclamation, and training cats, the main subjects of the evening, my interviewer finally found me. It all seemed so simple. We rehearsed questions and answers and she told me not to worry. Then she led me to the studio.

The heat struck me like a furnace and the light was intense. Cables and cameras were everywhere. Men with ear muffs wandered about muttering and smart young girls made notes. We moved to moulded plastic chairs beside a low black coffee table. There was no sign of a water jug. My throat began to close. Then the count down began. The casual coffee drinker became the cool professional news reader. My charming interviewer began to tense and her smile became fixed. A strange man rushed up to me and said "Hold still, while I powder your nose." At that point my composure left me. What were the questions? What were my answers? Why am I here?

And then it was over. A distant voice said "Thank you, doctor. Your views were both interesting and unusual." Eh! What had I said ? I could not remember. When I returned home, I asked my wife how I had done. "Don't speak to me," she said. "I've never been so upset. A brown tie with a blue suit. What will people think of me."WILLIAM THOMPSON (chief administrative medical officer, Lanarkshire). 